however, only part of child health surveillance: it must be supported by effective services for making a final diagnosis and for the subsequent treatment and management of the identified impairment before it becomes a handicap.

Next - why do we in the health services hold parents in such poor esteem? Parents are responsible for their children's health 365 days a year and on the whole do it very well-they deal with $90 \%$ of their children's illnesses without going near the health services, ${ }^{4}$ and yet we seem to refuse to show them respect for this by allowing them to keep their own children's health and development records. We cry "But they'll lose them," yet French parents of all social classes do not lose them and nor do New Zealand parents or those African populations where they are used. Furthermore, some studies suggest that using parent observations, both on their children's vision and hearing, greatly aids in the identification of problems. ${ }^{5}$

The second clinical task of the community child health services is the management, support, and treatment of children with special needs and their families. Unless the parents themseles can communicate the special needs of their own child to whoever looks after the child-teacher, grandmother, playschool leader, or childminder-then the medical services have failed. If we have not informed the parents in such a way that they understand their child's needs and can transfer this information to others, then something is wrong. This is another reason for making the parents the holders of the health record on each child as an added resource for the parents to use when informing all these people.

Though the overall incidence of handicap has remained much the same (except perhaps with the increased incidence of diabetes and a small but important group coming from intensive care baby units), the prevalence at specific ages is increasing because children with handicaps are living longer. The technological means of helping handicapped children are improving enormously, giving them the chance of better mobility and better communication. The Education Act 1981 is moving children with special needs out of special schools into either special units within mainstream schools, mainstream schools themselves, or a combination of both. This has often increased the time spent travelling by those offering therapeutic support, increased the number of other professionals that the medical services have to deal with, and increased the need for specialised equipment, all on a great many different sites. ${ }^{6}$

None of these three factors has been allowed for in the government's financing of the health services; as a result, in many districts the facilities for handicapped children are grossly underfunded. This has led in some cases to bitter battles over budgets by people who used to be colleagues with amicable relationships. The trend for families to resort to litigation to provide resources for the care of an individual handicapped child must reflect, in part, the present lack of adequate funding of facilities. In practical terms the current lack of resources ought to lead to more cooperation than ever between social services, education, and the health services to provide for children, whether they be handicapped, abused, or normal. Without such cooperation much time is wasted passing requests for equipment or professional support from once service budget to another, rather than trying to pool the meagre resources that are available.

Finally, policies for all children can be correctly formulated only if we have systems which allow us some pieces of basic information, on a whole population basis. This has been begun with the production of certain performance indicators, but we need to go further. If we are to run efficient services in terms both of benefits for the child population we serve and of money provided for the NHS then we must have information systems which tell us about trends, about age groups, about degrees of disability, about the ages at which children are identified, who identifies them, and the final diagnosis.

Just as essentially, we must also be able accurately to record what services children with special needs require and what services we can actually provide. And if what we are able to provide falls further and further short of what is required this may then be accurately recorded and advertised.

Without these developemnts the wranglings will go on, morale among all those concerned in the care of children will get even worse, the community child health services will deteriorate, and the most vulnerable section of our population will suffer.

AIDAN MACFARLANE

Consultant Community Paediatrician,

Community Health Offices,

Redcliffe Infirmary,

Oxford OX2 6HE

1 Macfarlane A, Pillay U. Who does what, and how much in the preschool child health services in England? BrMed F 1984;289:851-2.

2 Vanderboorde J, ed. European Committee 1985, child health surveillance. Strasbourg: Council of Europe Publication Section, 1985, and London: HMSO, 1985.

3 World Health Organisation European Working Group. Today's health-tomorrow's wealth, new perspectives in prevention in childhood. Summary report, Kiev, 21-25 October 1985. Geneva: World Health Organisation, 1985. (ICP/MCH 102/m04(s)6981F.)

4 Spenser N. Parents' recognition of the ill child. In: Macfarlane A, ed. Progress in child health vol 1. Edinburgh: Churchill Livingstone, 1984:100-12.

5 Hall S, Pugh A, Hall D. Vision screening in the under-5s. Br Med f 1982;285:1096-8.

6 Macfarlane A. The Education Act 1981. Br Med f 1985;290:1848-9.

\section{Bladder dysfunction in progressive autonomic failure}

When disturbances of continence or micturition occur in middle age the most likely diagnosis in men is prostatic obstruction and in women stress urinary incontinence. In either of these circumstances the patient's symptoms may be completely resolved by appropriate surgical intervention. It is important to recognise, however, that a much less common disease exists which mimics these disorders in its presentation but responds poorly to surgery. Characterised by primary degeneration of autonomic neurones, it is termed progressive autonomic failure. Often this disorder occurs in conjunction with more widespread degeneration of the central nervous system-multiple system atrophy.

Progressive autonomic failure was first described under the title "idiopathic orthostatic hypotension" by Bradbury and Eggleston, ${ }^{1}$ though it was Shy and Drager who first noted in a necropsy study of two cases that autonomic failure may be linked with a degeneration of the intermediolateral column cells in the spinal cord. ${ }^{2}$ In the cases they described there was a widespread disturbance of nervous function, which they attributed to selective degeneration in other parts of the brain including the corpus striatum, the substantia nigra, and the pontine nuclei. The condition was originally known as the Shy-Drager syndrome, but as neurological features they did not recognise have been added it is now usually known as "progressive autonomic failure with multiple system atrophy." Recently it has been recognised 
that a specific group of cells in the anterior horn of the sacral spinal cord, known as Onuf's nucleus, may also be affected in the disease. ${ }^{3}$

Progressive autonomic failure with multiple system atrophy has an insidious onset. The first urinary symptoms are usually frequency and urgency, soon progressing to urge incontinence; men also complain of erectile impotence and failure of ejaculation. Eventually orthostatic hypotension supervenes and this, together with urinary incontinence, constitutes the most disabling feature of the syndrome.

On examination the bladder is usually impalpable, but the tone of the anal sphincter is reduced. The most important general physical sign of autonomic failure is a pronounced fall in blood pressure on standing. An intravenous urogram will generally show normal upper tracts, but the bladder is trabeculated and invariably there is incompetence of the proximal urethra - a feature which may be seen more easily on a cystogram with the patient erect. A cystometrogram will show involuntary detrusor contractions during filling of the bladder; but the magnitude of these is reduced in more advanced cases. The ability to produce a voluntary bladder contraction appears to be lost early in the disease. The explanation for these findings probably lies in the degenerative changes that affect the basal ganglia and midbrain; both the corpus striatum and the pontine nuclei have been shown to influence bladder activity in studies on animals. ${ }^{4}$ These more central effects are undoubtedly compounded by progressive loss of cells from the preganglionic autonomic neurones of the thoracolumbar and sacral spinal segments, which will eventually result in a decentralised bladder akin to that seen after injury to the pelvic nerves.

Patients who suffer from progressive autonomic failure with multiple system atrophy show a characteristic inability to contract the distal urethral sphincter to prevent urinary leakage. Electromyography of the urethral sphincter has confirmed that the innervation of the striated muscle of the urethra is severely affected in this disease. ${ }^{5}$ This seems to be the result of neuronal degeneration of Onuf's nucleus, which has been shown in experimental animals to be responsible for the innervation of the striated muscle of both anal and urethral sphincters. ${ }^{6}$ Why the motor neurones of Onuf's nucleus should be selectively affected in this condition while other anterior horn cells are largely spared is a matter for speculation. The converse seems to apply in motor neurone disease: amid severe generalised loss of anterior horn cells Onuf's nucleus remains intact. Clearly these cells differ in some fundamental way from other motor neurones.

The striated muscle of the urethral sphincter differs from other skeletal muscles in showing tonic electromyographic activity which persists even during sleep and light general anaesthesia. The only structure that bears close comparison is the cricoarytenoid muscle of the larynx, which is constantly active in order to maintain abducture tone-and this muscle, too, suffers denervation in patients who have progressive autonomic failure with multiple system atrophy. ${ }^{7}$ Conceivably, then, it is the property of tonic firing of these neurones-located in Onuf's nucleus in the case of the urethral sphincter, and in the nucleus ambiguus in the case of the larynx-that distinguishes them from the neurones of other skeletal muscles.

Since the degenerative neuronal loss that occurs in progressive autonomic failure and multiple system atrophy cannot be arrested, treatment of the bladder disturbances is at best supportive. Most important is the recognition of the diagnosis and avoidance of transurethral surgery, which inevitably exacerbates patients' symptoms. Unfortunately cholinergic agents do not seem to improve voluntary bladder contractions, and, though sympathomimetic drugs may

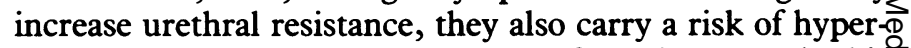
tension owing to the supersensitivity of agonist agents in thise disorder. Eventually urinary incontinence may need to bẹ treated by external urinary appliances in men and indwelling urethral catherterisation in women. The poor prognosis of patients suffering this condition generally rules out treat-s ment by implantation of artificial urinary sphincter devices.

Senior Urological Registrar,

Middlesex Hospital,

London WIN 8AA

Consultant Neurologist,

National Hospital for Nervous Diseases,

London WCIN 3BG

1 Bradbury A, Eggleston C. Postural hypotension: a report of three cases. Am Heart $\mathcal{f}$ 1925;1:73-86. 2 Shy GM, Drager GA. A neurological syndrome associated with orthostatic hypotension. ArchO Neurol 1960;2:511-27.

3 Sung JH, Mastri AR, Segal E. Pathology of the Shy-Drager syndrome. I Neuropathol Exp Neuro 1978;38:253-68.

4 Kuru M. Nervous control of micturition. Physiol Rev 1965;45:425-94.

5 Kirby RS, Fowler CJ, Gosling JA, Bannister R. Vesico-urethral dysfunction in progressiven autonomic failure with multiple system atrophy. F Neurol Neurosurg Psychiatry 1986;49:554-62. U

6 Kuzuhara S, Kanazawa I, Nakanishi T. Topographical localization of Onuf's nuclear neurones innervating the rectal and vesical striated sphincter muscles: a retrograde fluorescent doublo labelling in cat and dog. Neurosci Lett 1980;16:125-30.

. Laryngeal electromyography in multiple system atrophy with autonomic failure. $\mathcal{F}$ Neurol Neurosurg Psychiatry 1981;44:49-53.

\section{Graduated elastic stockings}

Elastic support stockings are of proved value in overcoming the effects of prolonged venous hypertension..$^{12}$ If the valves of the deep veins or calf perforating veins have becom\& incompetent or if segments of the deep veins are occlude $\vec{E}$ after a thrombosis the high venous pressure developed by the calf muscle pump during standing or walking cannot be lowered effectively. ${ }^{3}$ The persistently raised venous pressure distends the dermal capillary bed ${ }^{4}$ and encourages larges macromolecules (including fibrinogen), which are normallye held within the vascular compartment, to escape into the tissues. $^{5}$ This is seen clinically as the development of lipodermatosclerosis, which precedes the development of venous ulceration. ${ }^{6}$

Elastic compression applied to the calf raises the loca interstitial pressure and decreases the superficial venous pressure, thereby reducing the leak of solutes and fluid into the interstitial space. The stockings also improve the venous return, seen as an increase in flow velocity through unocclu슈 ded deep and superficial veins. ${ }^{78}$ Compression enhances theु local release of plasminogen activator, ${ }^{9}$ which initiates extras vascular dissolution of fibrin and is therefore of potentias benefit in restoring defective fibrinolysis and stimulating thẹ breakdown of pericapillary fibrin deposits responsible for the lipodermatosclerosis. ${ }^{10}$ All forms of compression squash the superficial venous channels and so relieve discomfort by preventing the excessive venous distension found in patients with varicose veins.

The first efforts to provide extrinsic calf compression wer\& made in the seventeenth century with rigid lace up stocking? applied over the lower calf in an attempt to heal ulceration. Elastic stockings in some form are thought to have been usect for over 150 years, but Sigg credits Van der Molen with the 